\title{
Damage control orthopaedics
}

\section{Introduction}

Emergency procedures aimed at rapid reduction and fixation and spanning of periarticular fractures has been termed "damage control orthopaedics".

There was always a debate between early total care (ETC) and damage control orthopedics (DCO). Early fixation of femoral fractures was shown to have better outcome and less pulmonary complications. The arguments for early fixation of femoral fractures is to minimize hemorrhage from fracture site, prevent ongoing soft tissue damage and minimize systemic inflammatory activation, which reduces secondary lung complications.

Bone et al. ${ }^{1}$ showed in prospective clinical trial that patients underwent definitive femoral fracture stabilization within 24 hours of admission in the hospital showed significant reduction in long complications when compared to patients which were delayed.

In severely injured patients early definitive fixation of fractures may not be appropriate. Pape et al. ${ }^{2}$ showed that in the multiple trauma patients, with chest injury, early total care (ETC) resulted in more pulmonary complications.

The argument for damage control orthopaedics (DCO) is to minimize the second hit to systemic inflammatory system, which was due to surgical intervention caused by the surgical stabilization of fractures. Maximum authors categorize the multiple injured patients into 4- groups which are-

\section{Stable}

2. Border line

3. Unstable

4. In extremis based on their level of injuries and physiological response at time of presentation.

Recent studies showed that for management of multiple trauma patients, ETC is appropriate in stable and borderline multiple injured patients and DCO is the best options for management of patients in the unstable and in extremis. ${ }^{3,4}$

So debate should not be which management is better but which patients would be better treated with either ETC or DCO. A practical approach is to quantity the physiological response to resuscitation in the multiple trauma patients.

Vallier et al. ${ }^{4}$ applied the term early appropriate care; they studied 1442 patients with pelvic, spinal and femoral fractures, the patients underwent comprehensive resuscitation prior to definitive surgical intervention and fixation. Patients with lactate level $<4.0 \mathrm{~mm} / \mathrm{l}, \mathrm{pH}$ $>7.25$ base excess $>5.5 \mathrm{~mm} / 1$ post resuscitation were safe to proceed with definitive fixation.

Patients, who were not responsive to resuscitation, where the lactate, $\mathrm{PH}$ and base excess were worsening, were treated with DCO.

Volume 6 Issue 5 - 2016

\author{
Bari MM,' Shahidul Islam, ${ }^{2} \mathrm{NH}$ Shetu, ${ }^{2}$ \\ Mahfuzer Rahman ${ }^{2}$ \\ 'Bari -Ilizarov Orthopedic Centre,Visiting and Honored Prof. \\ Russian Ilizarov Scientific Centre, Bangladesh \\ ${ }^{2}$ Bari-llizarov Orthopaedic Centre, Bangladesh
}

Correspondence: Bari MM, Bari-llizarov Orthopaedic Centre, 72, Satmasjid Road, Nizams Shankar Plaza, Dhanmondi, Dhaka, Bangladesh, Tel 880000000000 Email bari.ilizarov31@gmail.com

Received: October 24, 2016 | Published: November 25, 2016

\section{Case presentation}

Moazzem Hossain, 34 years old male, Sustain injury on 20.10.2016 at 11:00 am in Bogra district $205 \mathrm{~km}$ from Dhaka. He was taken to Bogra Medical College Hospital where he got primary management by plaster and antibiotics and 2 units of blood $(900 \mathrm{ml})$. Then he was referred to Dhaka for better management. I received the patient at my BARI-ILIZAROV ORTHOPAEDIC CENTRE, Dhanmondi, Dhaka at 09:00 pm. After taken the proper anamnesis I have done all investigations accordingly. Then the patient was taken to OT for further management. X-ray shows: 1 . Comminuted fracture left shaft of femur, 2. Medial condylar fracture of femur ipsilateral (was found by fluoroscopy in OR), 3. Comminuted fracture left tibia with comminuted fracture left fibula G IIIA, 4. Left wrist sprain, 5. Contusion of head. The patient was in a shock. BP was: 70/60 mm of Hg. Pulse was 140/minutes. 2 units $(900 \mathrm{ml})$ of blood was transfused per operatively and 2 units (2 liters) of Hartmann's Solution (Sodium Chloride: BP $0.6 \% \mathrm{w} / \mathrm{v}$, Potassium Chloride: BP $0.04 \% \mathrm{w} / \mathrm{v}$, Calcium Chloride: BP $0.027 \% \mathrm{w} / \mathrm{v}$, Sodium Lactate: USP $0.32 \% \mathrm{w} / \mathrm{v}$ ) intravenously infused (Figure 1).
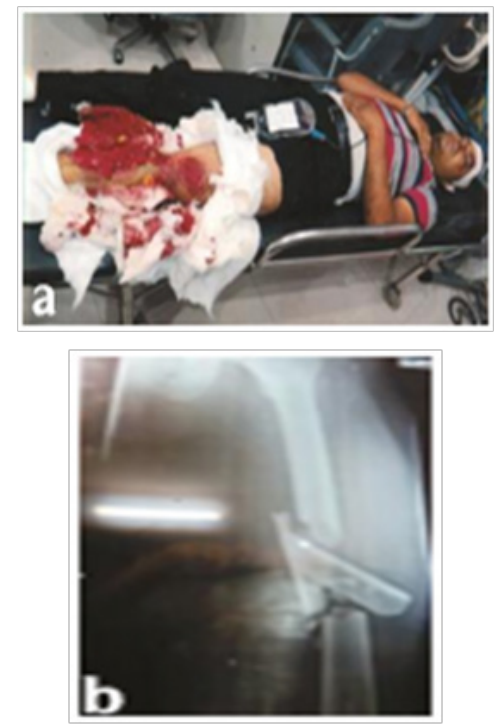

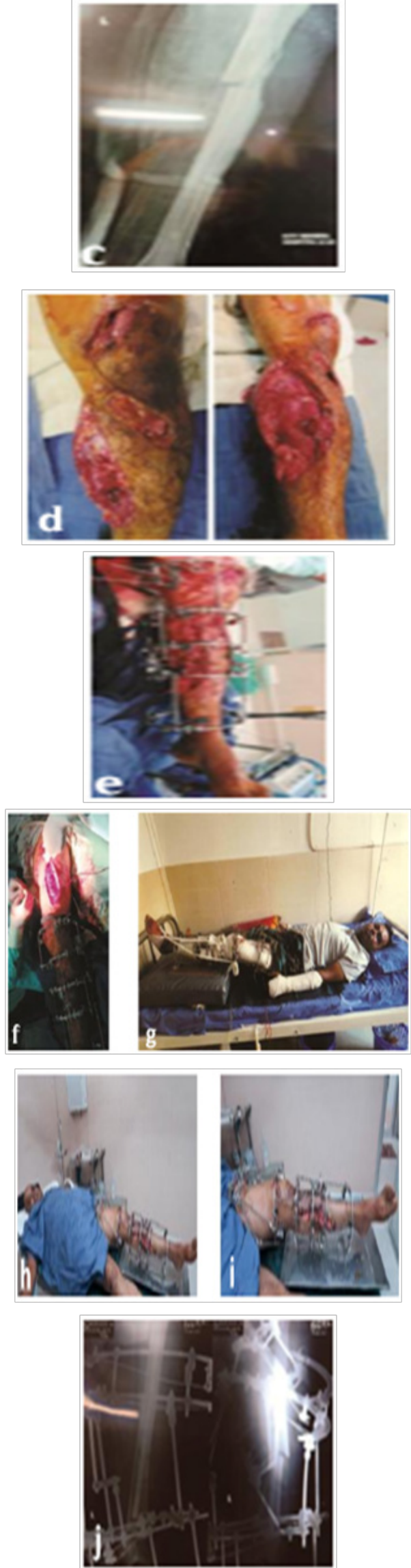
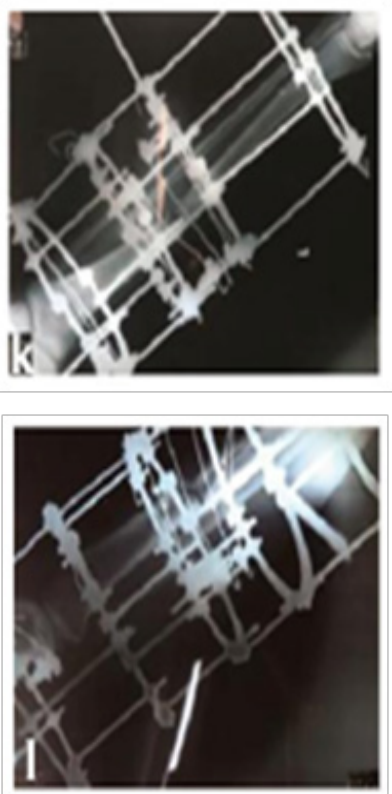

Figure I Case I

a. Received the patient 10 hours after injury in my consultation room.

b. Comminuted fracture left femoral shaft.

\section{Conclusion}

ETC, and DCO have their place in the management of multiple trauma patients. Comprehensive resuscitation is mandatory for improving end-organ hypoperfusion.

\section{Acknowledgments}

None.

\section{Conflicts of interest}

None.

\section{References}

1. Bone LB, Johnson KD, Weigelt J et al. Early versus delayed stabilization of femoral fractures. A prospective randomized study. J Bone Joint Surg Am. 1989;71(3):336-340.

2. Pape HC, Hildebrand F, Pertschy S et al. Changes in the management of femoral shaft fractures in polytrauma patients: from early total care to damage control orthopedic surgery. $J$ Trauma. 2002;53(3):452-461.

3. Nicholas $\mathrm{B}$, Toth $\mathrm{L}$, van Wessem $\mathrm{K}$ et al. Borderline femur fracture patients: early trauma care or damage control orthopaedics? ANZ J Surg. 2011;81(3):148-153.

4. Vallier HA, Wang X, Moore TA et al. Timing of orthopaedic surgery in multiple trauma patients: development of a protocol for early appropriate care. J Orthop Trauma. 2013;27(10):543-551. 